\title{
SELECTION OF A LAYOUT CONFIGURATION FOR RECONFIGURABLE MANUFACTURING SYSTEMS USING THE AHP
}

\author{
M. Reza Abdi \\ Bradford University School of Management \\ Emm Lane, Brdford, BD9 4JL, U.K. \\ r.abdi@bradford.ac.uk
}

Key words: AHP, Reconfigurable Manufacturing Systems (RMSs), layout

Summary: Reconfigurable Manufacturing Systems (RMSs) are designed to rapidly respond to changing market requirements. RMSs operate on various products grouped into families according to their operational requirements. Therefore, an RMS may require different layout configurations while switching from one product to the other. This paper investigates the criteria, which can influence on choosing layout configurations. It then develops an AHP model to structure the criteria for the selection of the most appropriate layout for each configuration stage. The criteria are defined based on the layout reconfigurability, cost, quality and reliability. The alternatives are identified based on the serial / parallel configurations of the given machines.

\section{Introduction}

The changes of customer requirements create a need for new designs of manufacturing systems. In order to sustain competitiveness in dynamic markets, manufacturing organisations should provide the sufficient flexibility to produce a variety of products on the same system (Chick et.al. 2000). In this way, advanced manufacturing systems need to accurately consider economical aspects as well as engineering aspects; otherwise, they cannot obtain a reasonable share of competitive market to justify their investments.

RMSs are designed to rapidly produce different product families in the shortest time and at the lowest cost without sacrificing quality. The major characteristic of such systems is called reconfigurability, which is the ability of rearranging and/or changing manufacturing elements aimed at adjusting to new environmental and technological changes. Similarly, manufacturing reconfigurability has shortly become a new economic objective along with classical objectives such as low cost and high quality. Koren et.al. (1999) defined a RMS as 'a manufacturing system designed at the outset for rapid changes in structure as well as in hardware and software components in order to quickly adjust production capacity and functionality within a part family in response to sudden changes in market or in regulatory requirements'. Zhao et.al. (2000) considered a RMS as 'a manufacturing system in which a variety of products required by customers are classified into families, each of which is a set of similar products that corresponds to one configuration of the RMS'.

An RMS is expected to be able to rapidly adjust to new circumstances by rearranging and/or changing its hardware and software components in order to accommodate not only the production of a variety of products, which are grouped into families, but also the new product introduction within each family (Abdi and Labib, 2003). The manufacturing system is then required to be reconfigurable in capacity for volume changes and functionality for family changes.

Modularity is a basis for product/process design of an RMS. A modularity-based structure must be an objective in the layout design stage enabling RMSs to produce product variants. This characteristic allows manufacturing systems to produce high product variety (Huang and Kusiak, 1997). As a result, an RMS must be upgradeable in process technology with new operational requirements and able to adjust capacity quickly whilst changing product types. 
The RMS design problem can be decomposed into different sub-problems such as measuring flexibility, system configuration, cost estimation, and layout configuration. The same set of machines under different configurations lead to different system throughputs, and for the same layout the determination of the types and number of machines will affect the efficiency of the manufacturing system. Therefore, the measurement of tangible and intangible aspects of an RMS design needs a quantitative and qualitative decision-making process.

\section{Layout Configuration}

Mathematical programming has been frequently used for layout configuration for different types of manufacturing systems by various researchers. Cheng and Chen (1996) proposed a simple quadratic assignment formulation to minimise the total distance between machines within manufacturing cells. Taboun et.al. (1998) presented a mixed integer programming formulation of the problem, which aimed to minimise the cell configuration costs, machine capital investment costs, machine procurement and salvage costs, idle time costs, inter-cell movement costs and part subcontracting costs. Bazargan-Lari (1999) discussed layout design problem and noted The author also emphasised that goal programming was one of the solution methodologies for making decision for layout design. Kirk and Tebaldi. (1997) illustrated a perspective of production facility layout for agile manufacturing systems. The authors emphasised maximum life -time profitability rather than minimum cost or even minimum life-cycle time.

Classical layout models have been proposed to minimise material handling cost for a single product system. The classical mathematical models can be developed for multi-product systems via considering product type as a new parameter. Benjaafar (1999) developed the facility layout design considering product type as a design parameter. Because of complexity of the model, only heuristic models can be used for solving the proposed model.

In an RMS, products must be grouped into families and then the appropriate product family at each reconfiguration stage must be allocated to the corresponding layout configuration. A reconfigurable layout is a substantial aspect of an RMS. Since material flow volumes are determined by the product routing sequences, a configurable layout should ideally provide equally efficient travel for all product families. In other words, regardless of the operational sequence different RMS departments must be visited by a product family. This can be achieved by letting each department be easily accessible from any other department. In addition, an RMS layout must hold a closed connection with the material handling system. Each layout configuration needs a material handling system and enforces a material handling cost.

To select a layout configuration for an RMS, a decision making approach can be applied to evaluate the objectives, criteria, and feasible layout alternatives. Since the selection of a layout configuration is a multi- criteria decision problem, the Analytical Hierarchical Process (AHP) can be used. The AHP developed by Thomas Saaty (1980), is one of the multi-criteria decision making approaches that decomposes a complex problem to a hierarchical order. Not many researchers have applied the AHP for the design and planning of manufacturing systems. The AHP has been applied for selecting plant layout configuration such as group technology, transfer lines, and functional layout with respect to the defined objectives and their preferences. For example, Abdul-Hamid et.al. (1999) suggested an AHP model for the selection of best layout based on three main objectives: flexibility, volume, and cost using a knowledge-based system.

\section{The Proposed AHP Model}

In this section, a hierarchical framework is proposed to select the layout configuration for a RMS design through a case study. The AHP model is hierarchically structured as depicted in Table 1 . The main goal (level 0) is to select the most preferred layout configuration. For the selection of a layout configuration, the following objectives are identified: 
and variety facilitate the validation of the ranking procedure. The qualitative and quantitative criteria are evaluated with respect to the higher level objective by using the same scoring approach. To clarify the scoring approach, three basic levels of importance Low (L), Medium (M), and High (H) can be used for the evaluation of criteria with respect to each objective, as shown in Table 2.

\begin{tabular}{|c|c|c|c|c|c|c|}
\hline Layout configuration & 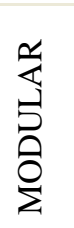 & 䒺 & 悶 & 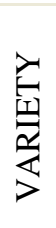 & 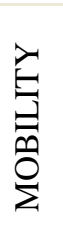 & 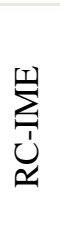 \\
\hline CON1 & M & $\mathrm{H}$ & $\mathrm{L}$ & $\mathrm{L}$ & M & M \\
\hline CON2 & M & L & M & M & $\mathrm{H}$ & M \\
\hline CON3 & M & M & M & $\mathrm{H}$ & M & $\mathrm{H}$ \\
\hline
\end{tabular}

Table 2 Product families ranked for each criterion with respect to market requirements

\section{Results and Analysis}

Once the model is built, the next step is to evaluate the elements by making pair-wise comparisons with respect to the element(s) at the higher level(s) of the hierarchy. To achieve an evident numerical result of the proposed AHP model, the relative importance of each criterion with respect to each objective is determined based on the author's viewpoints. Running the model, the assessment process creates a synthesis judgement that combines all the separate judgements and priorities leading to the defined alternatives.

The proposed AHP model is examined through a case study using the Expert Choice package (Expert Choice,1999). As shown in Figure 1, the hybrid layout (CON3) is the most appropriate configuration for the case study. It can be seen that CON3 is preferred to CON1 and CON1is preferred to CON2 (CON3 > CON1> CON2) with overall weights 0.373, 0.329, 0.297 respectively.

\section{Layout Selection}

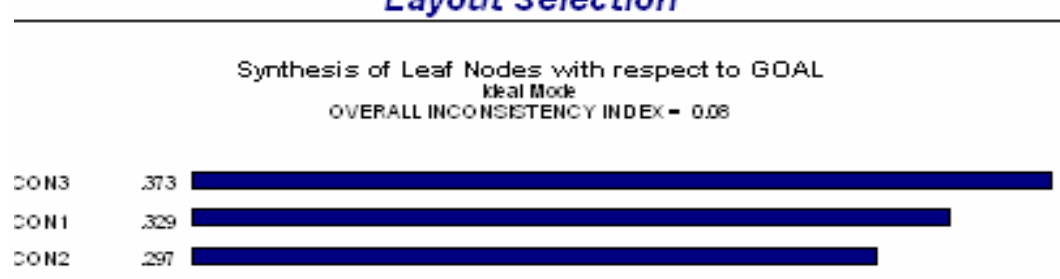

Figure 2 The layout solution for the AHP model

The alternative layouts may have different preferences with respect to different criteria. As shown in Figure 3, the layout configurations have different priorities with respect to layout reconfigurability (LAYCONF). The hybrid layout (CON3) has the highest priority and an increase in the LAY-CONF priority with respect to the goal will justify the same layout configuration. On the other hand, the alterative 
solutions with respect to material flow result in CON1>CON2>CON3. It means that the serial layout has a more fluent material flow in the system.

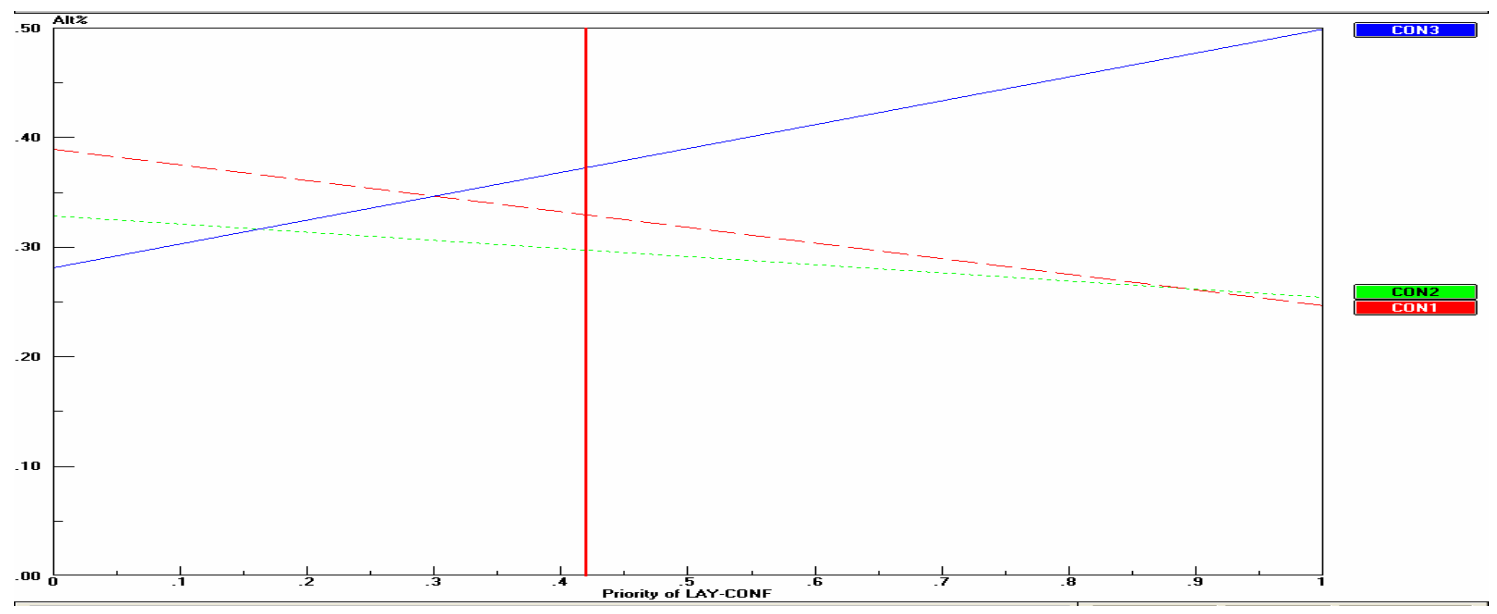

Figure 3 Alternative solutions with respect to layout reconfigurability

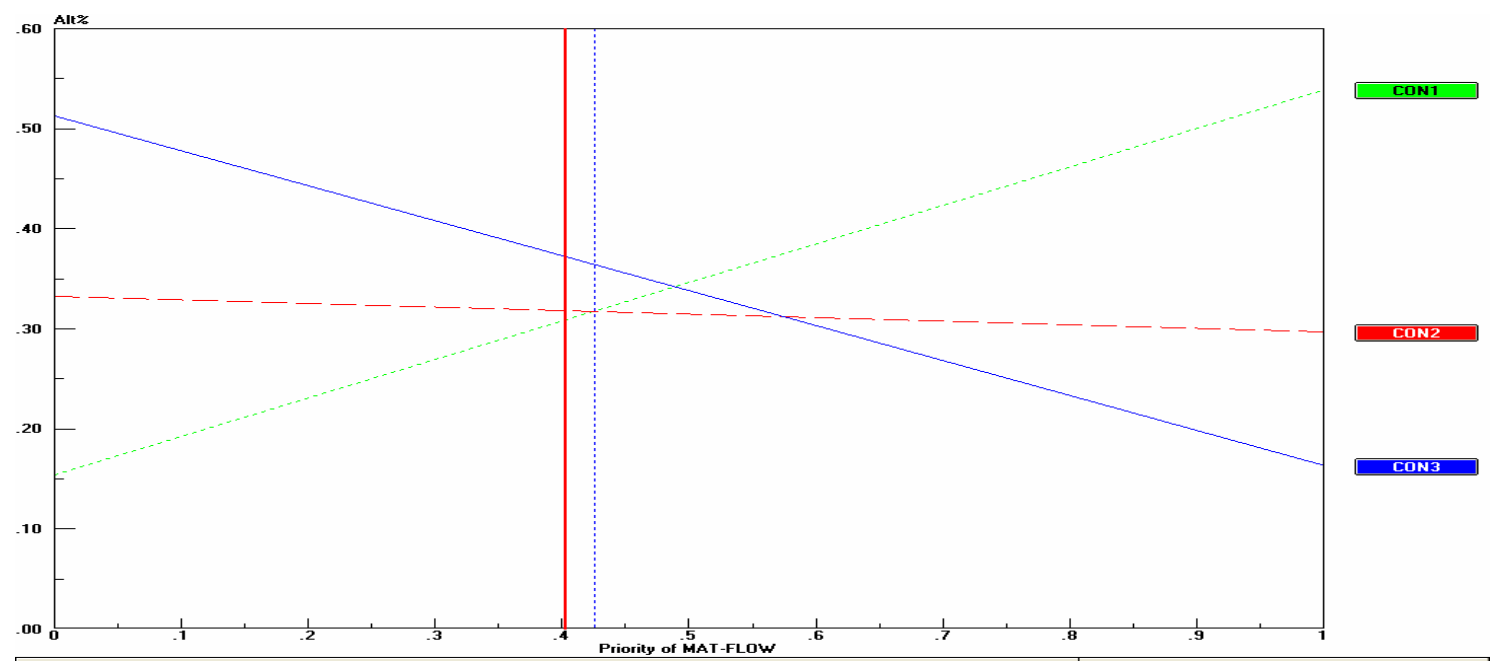

Figure 4 Alternative solutions with respect to material flow

\section{Conclusion}

The paper develops an AHP model for the selection of layout configurations of an RMS. The AHP model is proposed to take into account both quantitative and qualitative criteria of reconfiguability, cost, quality and reliability. The proposed AHP model is examined and analysed through a case study using the Expert Choice package. The AHP model is developed to determine the efficient configuration of manufacturing facilities for the production of the product families in the production range. Three layout configurations for the three machines are defined as alternatives for the case study. The sensitivity analysis is presented to highlight the configuration solutions with respect to layout reconfigurability as the most important criterion. 


\section{References}

Abdi, M.R., Labib, A.W. (2003), “A design strategy for Reconfigurable Manufacturing Systems (RMSs) using the Analytical hierarchical Process (AHP): a case study”, International Journal of Production Research, Vol. 41, No. 10, pp. 2273-2299.

Abdul-Hamid, Y.T., Kochhar, A.K., Khan, M.K. (1999), “An analytic hierarchy process approach to the choice of manufacturing plant layout”, Proceedings of the Institute of Mechanical Engineers, Vol. 213, Part B, pp. 397-406.

Bazargan Lari, M. (1999), “Layout design in cellular manufacturing”, European Journal of Operational Research, Vol. 112, No. 2, pp. 258-272.

Benjaafar, S. (1999), “Design of Agile Factory Layout”, Flexible Automation and Intelligent Manufacturing Proceeding of Ninth International FAIM Conference, pp. 425-427.

Cheng, C.H., Chen, Y. (1996), “Autonomous intelligent agent and its potential applications”, Computers \& Industrial Engineering, Vol. 31, No. 1-2, pp. 409-412.

Expert Choice (1999), Expert Choice Software, Expert Choice Inc., Pittsburgh, PA.US.

Koren, Y., Heisel, U., Jovane, F., Moriwaki, T., Pritschow, G., Ulsoy, G., VanBrussel, H. (1999), "Reconfigurable manufacturing systems", Annals of the CIRP, Vol. 48, pp 1-14.

Krik, S., Tebaldi, E. (1997), “Design of robotic facilities for agile automobile manufacturing”, Industrial Robot, Vol. 24, No. 1, pp. 72-77.

Saaty, T.L. (1980), The Analytical Hierarchical Process, McGraw Hill, New York.

Taboun, S.M., Merchawi, N.S., Ulger, T. (1998), “part family and machine cell formation in multi-period planning horizons of cellular manufacturing systems”, Production Planning \& Control, Vol. 9, No. 6, pp. 561-571.

Zhao, X., Wang, J., Luo, z., (2000), “A stochastic model of a reconfigurable manufacturing system, Part 1: A framework”, International Journal of Production Research, Vol. 38, No. 10, 2273-2285. 